\title{
Validation of new CFD release by Ground-Coupled Heat Transfer Test Cases
}

\author{
Stanislav Sehnalek ${ }^{1, \star}$ \\ ${ }^{1}$ Tomas Bata University in Zlin, Faculty of Applied Informatics, Department of Automation and Control Engineering, Nad \\ Stranemi 4511, Zlin, Czech Republic
}

\begin{abstract}
In this article is presented validation of ANSYS Fluent with IEA BESTEST Task 34. Article stars with outlook to the topic, afterward are described steady-state cases used for validation. Thereafter is mentioned implementation of these cases on CFD. Article is concluded with presentation of the simulated results with a comparison of those from already validated simulation software by IEA. These validation shows high correlation with an older version of tested ANSYS as well as with other main software. The paper ends by discussion with an outline of future research.
\end{abstract}

\section{Introduction}

Important parameter for building climate is temperature gains caused by internal and external heat sources. These gains affect comfort of people inside these buildings. A long-term research of peoples' comfort in 26 office buildings in five European Union countries was executed by [1]. Interior comfort can be provided by ventilation systems, by shading systems or by their combination. In recent years, there is a particular interest in sustainability of buildings [2] and [3]. Currently, there has been growing interest in lowering energy performance of buildings. This effort is also reflected in a new European directive, which instructs to construct near to zero energy sufficient buildings. Regardless of our experience and knowledge, there are always a risks of constructing an inconvenient building. To prevent this, appropriate design of building should be achieved. Thermal properties of a building could be calculated in a development phase, but it is limited to one-dimensional and rarely as two-dimensional problem solutions thanks to the complexity of buildings and the mathematical apparatus available. As a result of computational power increase in last decades, it is possible to design a model and implement mathematical simulation of thermal behaviour of a building also in threedimensional space [4]. For such mathematical simulation it is used computational fluid dynamic (CFD) [5]. Thanks to the expanding performance of computers, CFD is used for solutions as a convenient way to validate building's behaviour [6]. However, first of all it is important to validate thermal simulation programs [7]. Judkoff and Neymark developed a methodology for such intention in the middle of 90s [8]. Their approach is based on the analytical solution for steady-state heat flow through the floor slab. Although it was developed by Delsante, Stokes and

\footnotetext{
${ }^{\star}$ Corresponding author: sehnalek@ fai.utb.cz
}

Walsh [9], this problem has been in focus of researchers for some time [10]. Delsante's methodology focuses only on heat flow through solids and omits above grade constructions. Standard established by ASHRAE improved Judkoff's and Neymark's methodology by adding cases which focus mainly on above grade constructions and solar radiation [10], [11].

This paper returns to previous research of this phenomenon by authors. This time the focus is on validation of new release of ANSYS Fluent 18, nevertheless that FLUENT 6 was already validated. In methods section is included outline of cases from IAE BESTEST Task 34. In results chapter are summarized outcomes of simulations. Whole paper is concluded with discussion on results and outcomes.

\section{Methods}

International Energy Agency Building Energy Simulation Test methodology was developed by Judkof et. al. [8] in the middle of 90's. Combination of empirical validation, analytical verification and comparative analysis techniques are main proceedings of this methodology. It operates only with slab-on-grade heat transfer and became a stepping-stone for the other approaches, such as ANSI/ASHRAE Standard 140 improved adaptation developed by ASHRAE accordingly with American National Standards Institute (ANSI).

Methodology describes 17 cases of ground-coupled heat transfers designed to be compared with verified whole-building energy simulation software. Several of those already tested by IEA are EnergyPlus, FLUENT, Matlab, TRNSys and GHT. The first case, GC10a has its base in analytical solution and it is the simplest one of all cases. Furthermore, these cases are subdivided into three series, each with its own specification. For this paper were 


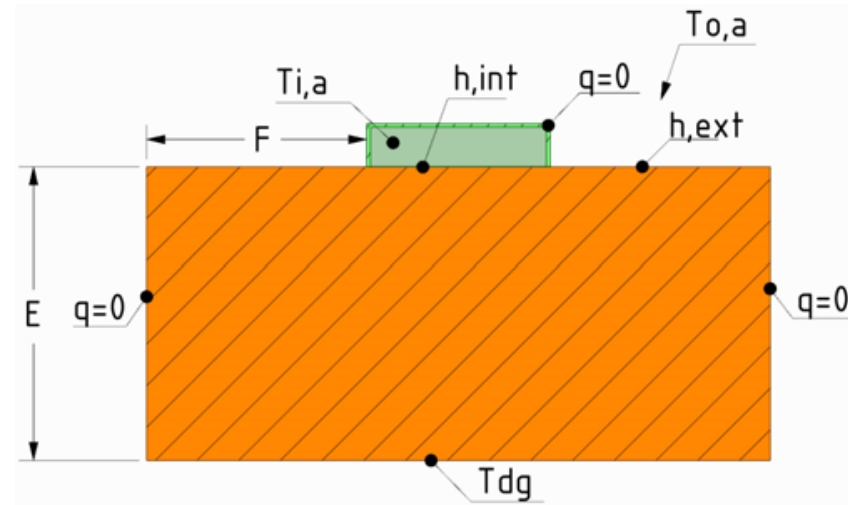

Fig. 1. Elevation section

chosen six cases where all are steady-state. As mentioned before, FLUENT has been tested in past, but for version 6.0.20, in this article is tested ANSYS FLUENT 18.0 [12].

\section{- Series a}

- The main purpose of this series is to validate wholebuilding simulation programs.

- Namely: TRNSYS 16.1, SUNREL-GC 1.14.01, FLUENT 6.0.20 and MATLAB 7.0.4.365.

- It is recommended to apply this series as the first one, if a tested software can run it.

- Series b

- In this series, parameters are adjusted for more limited whole-building simulation programs or standard.

- Namely: EnergyPlus 2.0.0.025 and ISO 13370.

- Provides basis for series "a" and "c".

- Series c

- This series is most narrowed in use of boundary conditions, because it serves only for comparison of BASESIMP with other software.

\subsection{Geometry}

Geometry is similar in most cases, except for several models, which will be described later. Figure 1 depicts the elevation section of the examined test model, where $F$ represents far field boundary distance, $E$ stands for deep ground boundary depth, $T_{d g}$ is deep ground temperature, $T_{o, a}$ is the outside air temperature, $T_{i, a}$ is the inside temperature and $h_{\text {int }}$ and $h_{\text {ext }}$ represents surface coefficients of convection [8].

Figure. 2 shows plan view of the proposed building with slab dimensions. These parameters are similar for all cases. Table 1 enlists geometrical properties for proposed cases, with inequality in GC10a, GC30a and GC30c, which vary in ground depth and far-field boundary distance [8].

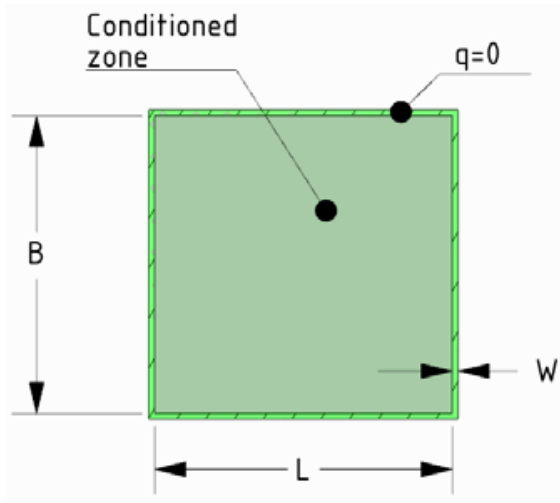

Fig. 2. Plan view

Table 1: Geometry properties.

\begin{tabular}{c|c} 
Parameter & Value $[\mathbf{m}]$ \\
\hline B & 12 \\
E & 15 \\
F & 15 \\
L & 12 \\
W & 0,24 \\
Building height & 2,7
\end{tabular}

Table 2: Thermal properties for soil, slab and above grade construction.

\begin{tabular}{l|c} 
& Soil and Slab \\
\hline Thermal conductivity $\left[\mathrm{Wm}^{-1} \mathrm{~K}^{-1}\right]$ & 1,9 \\
Density $\left[\mathrm{kg} \mathrm{m}^{-3}\right]$ & 1490 \\
Specific heat $\left[\mathrm{Jkg}^{-1} \mathrm{~K}^{-1}\right]$ & 1800
\end{tabular}

\subsubsection{Thermal properties}

Some of thermal properties are identical for all test cases aside from surface coefficients of convection, and these are enlisted in table 2 and 3.

Several parameters which are not present in table 2 also have to be taken into account:

- use slab thickness as low as software allows for a stable calculation;

- for software demanding below-grade foundation walls, use the same thermal properties as soil;

- surface radiation exchange is not included (if necessary set radiation to 0 or as low as possible);

- the ground surface and floor slab are on the same height level and both are considered to be flat and homogenous;

- for all cases water transmission via material should be turned off or reduced to its lowest level;

- adiabatic walls of the above construction are in contact with soil but do not penetrate it;

- no windows; 
- no infiltration or ventilation;

- no internal gains.

\subsection{Case specification}

In the following section are list of used cases. Parameters for each case are enlisted as well as changes against default configuration.

\subsubsection{Case GC10a - Steady-State Analytical Verification Base Case}

This case if the basic one and all the other are divided from it. It was derived by Delsante et al. [9] as 3 dimensional steady-state heat flow through the floor slab. This analytical solution method with comparison of simulation software could be taken as secondary mathematical truth standard.

$$
q=k\left(T_{i}-T_{o}\right) \frac{1}{\pi} F(L, B, W)
$$

\subsubsection{Rest cases}

The rest of used cases are summarized in table 3. For cases with "const $\mathrm{T}$ " was set boundary condition to constant temperature of surface insted of specification of heat transfer coefficient.

Table 3: Test specification

\begin{tabular}{ccccc} 
Case & $h_{, \text {int }}$ & $h_{, \text {ext }}$ & $\begin{array}{c}\text { Ground } \\
\text { Depth(E) } \\
{[m]}\end{array}$ & $\begin{array}{c}\text { Far-Field } \\
\text { Boundary (F) } \\
{[m]}\end{array}$ \\
\hline GC10a & const T & const T & infinite & infinite \\
GC30a & const T & const T & 30 & 20 \\
GC30b & 100 & 100 & 15 & 15 \\
GC60b & 7,95 & 100 & 15 & 15 \\
GC65b & 7,95 & 11,95 & 15 & 15 \\
GC30c & 7,95 & const T & 15 & 8
\end{tabular}

\subsection{ANSYS Fluent 18.0}

ANSYS Fluent is mainly used for determination of fluid flow by Navier-Stokes equations. It also contains energy calculations for heat transfer in fluids and solids as well as other parameters in scope of engineers [12].

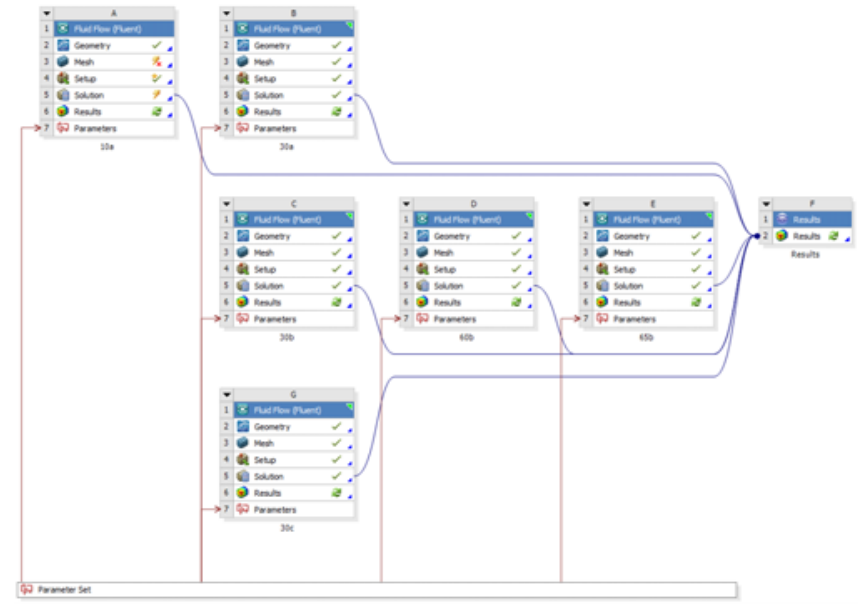

Fig. 3. Scheme of workbench configuration of cases.

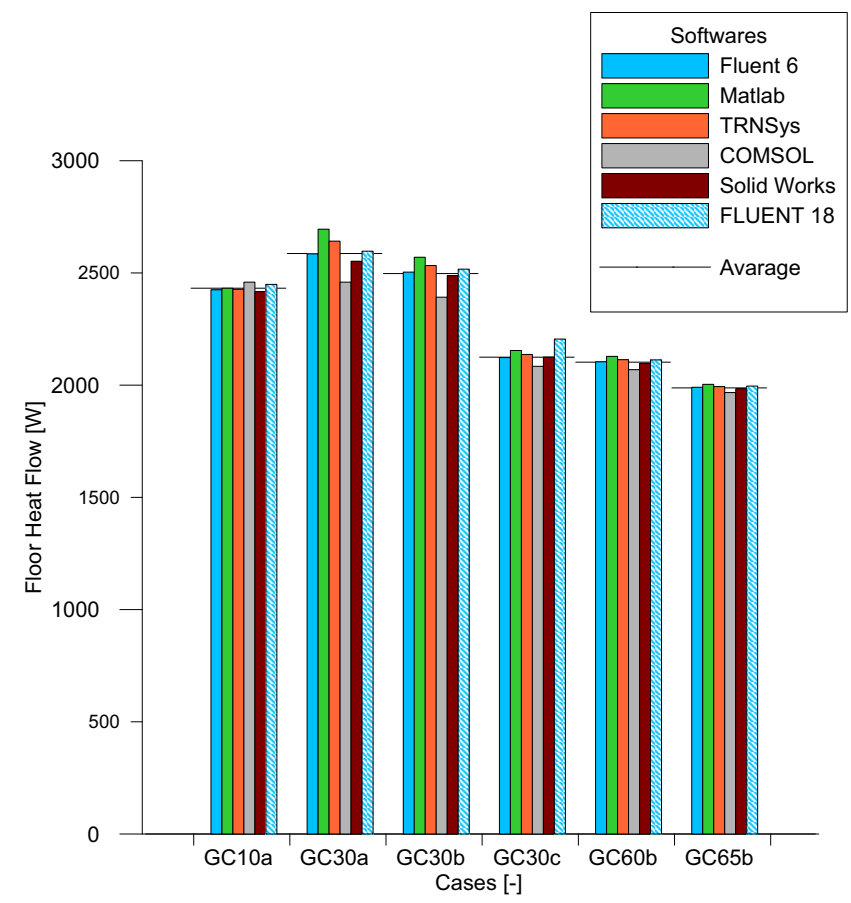

Fig. 4. IEA BESTEST Ground Coupling: In-Depth Floor Slab Steady-State Floor Conduction.

\section{Results}

Outcome of application of IEA BESTEST cases on FLUENT 18 will follow in this section. All mentioned cases were implemented by Workbench workspace with usage of parametrization and is depicted in Figure 3 [12].

\subsection{Application of cases on ANSYS Fluent}

This chapter deals with implementation of IEA BESTEST on ANSYS Fluent. Cases' main parameters initiation will be provided in subsections. First case is considered as parental for all the other cases and only changes in those will be mentioned. 
Table 4: Stationary test cases calculated by SW-FS.

\begin{tabular}{ccccc} 
Case & $\begin{array}{c}\text { FLUENT } \\
\mathbf{1 8}\end{array}$ & $\begin{array}{c}\text { Average } \\
\text { [W] }\end{array}$ & $\begin{array}{c}\text { Absolute } \\
\text { difference } \\
\text { [W] }\end{array}$ & $\begin{array}{c}\text { Relative } \\
\text { difference } \\
{[\%]}\end{array}$ \\
\hline GC10a & 2449 & 2435 & 6 & $<1$ \\
GC30a & 2597 & 2588 & 9 & $<1$ \\
GC30b & 2497 & 2501 & 4 & $<1$ \\
GC30c & 2125 & 2138 & 13 & 3 \\
GC60b & 2112 & 2104 & 8 & $<1$ \\
GC65b & 1988 & 1989 & 1 & $<1$
\end{tabular}

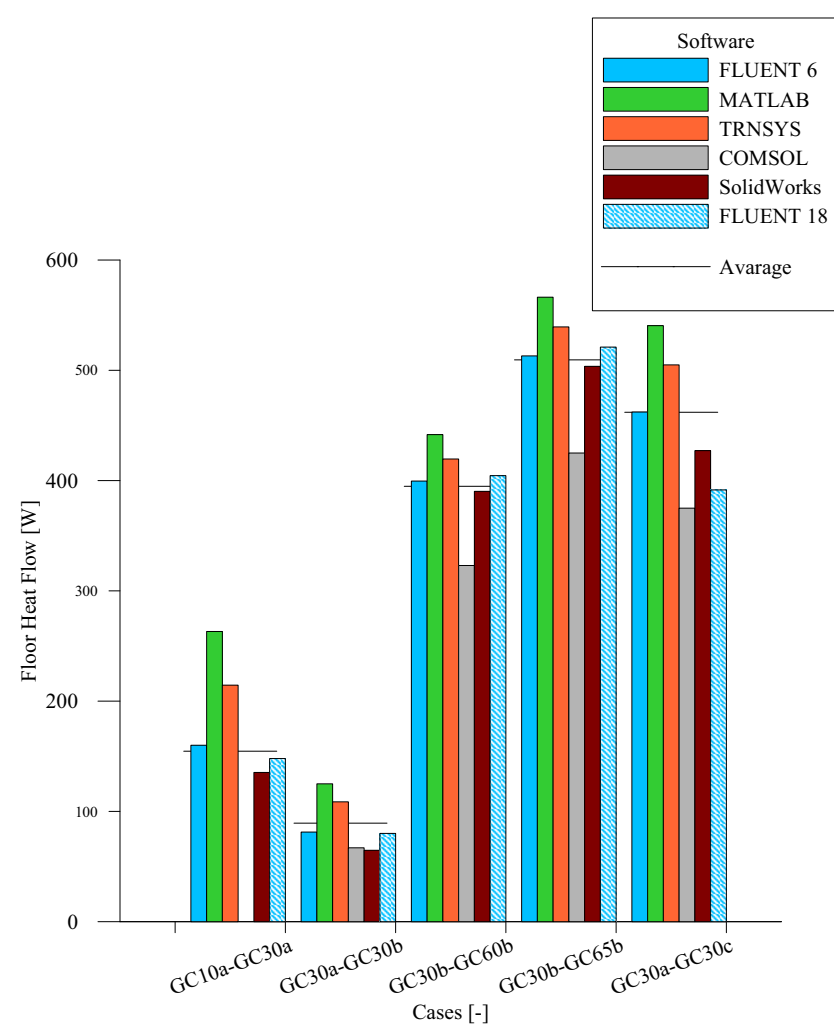

Fig. 5. IEA BESTEST Ground Coupling: In-Depth Floor Slab Steady-State Floor Conduction Sensitivity

Table 5: Stationary test case comparison calculated by ANSYS Fluent.

\begin{tabular}{lcccc}
\multicolumn{1}{c}{ Case } & $\begin{array}{c}\text { Fluent } \\
\mathbf{1 8} \\
{[\mathbf{W}]}\end{array}$ & $\begin{array}{c}\text { Average } \\
{[\mathbf{W}]}\end{array}$ & $\begin{array}{c}\text { Absolute } \\
\text { diff. } \\
\text { [W] }\end{array}$ & $\begin{array}{c}\text { Relative } \\
\text { diff. } \\
{[\%]}\end{array}$ \\
\hline $\begin{array}{l}\text { GC10a } \\
\text { - GC30a }\end{array}$ & 135 & 159 & 24 & 15 \\
$\begin{array}{l}\text { GC30a } \\
\text { - GC30b }\end{array}$ & 65 & 95 & 31 & 32 \\
$\begin{array}{l}\text { GC30b } \\
\text { - GC60b }\end{array}$ & 390 & 396 & 6 & 1 \\
$\begin{array}{l}\text { GC30b } \\
\text { - GC65b }\end{array}$ & 504 & 511 & 7 & 1 \\
$\begin{array}{l}\text { GC30a } \\
\text { - GC30c }\end{array}$ & 427 & 471 & 43 & 9
\end{tabular}



Fig. 6. Side view of temperature distribution.

After appropriate setup of the cases on Fluent, each case was executed. Results from simulation are shown in Figure. 4. Axis Y represents heat flows in Wats, on axis $\mathrm{X}$ are displayed used cases. The line at the top of each case is average without Fluent 18 taken in account. Results for EnergyPlus, FLUENT 6, Matlab and TRNSYS was taken from [8], results for COMSOL Multiphysics was taken from [13] and results for SolidWorks Flow Simulation (SW-FS) was taken from previous investigation of authors [14]. Results of case GC10a and GC30a was not provided for EnergyPlus.

Comparison of cases is displayed in Figure. 5. Axis $\mathrm{Y}$ is similar to Figure. 4, axis $\mathrm{x}$ represents odds between cases. Values were taken from same source as for Figure. 4. For this comparison EnergyPlus was excluded because of missing results in cases GC10a and GC30a. The evaluation for this comparison is presented in table 5. As can be seen differences vary from approximately $1 \%$ to $32 \%$.

Side view of temperature distribution is disclosed in Figure. 6. This state is for case GC30b with basic conditions. Other cases are similar only with little differences in distribution and geometry sizes. Temperatures are displayed in ${ }^{\circ} \mathrm{C}$ and vary from $10{ }^{\circ} \mathrm{C}$ for exterior to $30{ }^{\circ} \mathrm{C}$ for investigated slab.

\section{Conclusion}

The results indicate, overall, that new release has no changes to calculation. Main reason for difference between versions is generated mesh which influence solutions. Variation of $1 \%$ is very positive for such type of benchmark. As is documented in [11], there was variety from $9 \%$ to $55 \%$ disagreement between firstly tested software with the analytical solution. However, appropriate setup of mesh should be considered along with proper analysis after generation. As next step should follow testing on remaining 10 cases from IAE BESTEST. These are similar to already tested once, but they have sinusoidal variation of outside temperature. Further research should aim comprehensive ANSI/ASHRAE Standard 140, and properly validate ANSYS Fluent with it.

This work was supported by the Ministry of Education, Youth and Sports of the Czech Republic within the National Sustain- 
ability Programme project No. LO1303 (MSMT-7778/2014) and also by the Internal Grant Agency of Tomas Bata University in Zlin under the project No. IGA/CebiaTech/2017/002.

\section{References}

1. Nicol, F. and Humphreys, M. (2007). Maximum temperatures in European office buildings to avoid heat discomfort, Solar Energy 81(3): 295-304.

2. Butera, F. M. (2004). Glass architecture : is it sustainable ?, Passive and Low Energy Cooling for the Built Environment, number May 2005, Santorini, pp. 161-168.

3. Poirazis, H. (2004). Double Skin Fac,ades for Office Buildings Literature Review, Technical report, Lund.

4. Tsai, B.-j., Lin, S.-C. and Yang, W.-C. (2012). HVAC analysis of a building installed shape-stabilized phase change material plates coupling an active building envelope system, WSEAS TRANSACTIONS on HEAT and MASS TRANSFER 7(3): 79-90.

5. Tu, J., Yeoh, G. H. and Liu, C.. Computational Fluid Dynamics: A Practical Approach, (Elsevier Inc., 2008), ISBN 978-0-7506-8563-4,

6. Jarungthammachote, S. (2014). Entropy Generation Analysis of Transient Heat Conduction in a Solid Slab with Fixed Temperature Boundary Conditions, WSEAS TRANSACTIONS on HEAT and MASS TRANSFER 9: 9-18.

7. Lomas, K., Eppel, H., Martin, C. and Bloomfield, D. (1997). Empirical validation of building energy simulation programs, Energy and Buildings 26(3): 253-275.
8. Neymark, J. and Judkoff, R. (2008). In-Depth Diagnostic Cases for Ground Coupled Heat Transfer International Energy Agency Building Energy Simulation Test and Diagnostic Method ( IEA BESTEST ) In-Depth Diagnostic Cases for Ground Coupled Heat Transfer Related to Slab-on-Grade Construction, Technical Report September 2008, NREL, Golden.

9. Delsante, A. (1987). The Development of an Hourly Thermal Simulation Program for Use in the Australian Nationwide House Energy Rating Scheme.

10. Trethowen, H. and Delsante, A. (1998). Four-Year On-Site Measurement of Heat Flow in Slab-onGround Floors with Wet Soils, Thermal performance of the exterior envelopes of buildings VII(December): 487-499.

11. Judkoff, R. and Neymark, J. (2006). Model Validation and Testing: The Methodological Foundation of ASHRAE Standard 140, Technical report.

12. Ansys fluent user's guide (2017)

13. Gerlich, V., Sulovska, K. and Zalesak, M. (2013). COMSOL Multiphysics validation as simulation software for heat transfer calculation in buildings: Building simulation software validation, Measurement 46(6): 2003-2012.

14. Sehnálek, S., Zálešák, M., Vincenec, J., Opluštil, M., Chrobák, P. Evaluation of SolidWorks Flow Simulation by Ground-Coupled Heat Transfer Test Cases. In Latest Trends on Systems. Volume II. Rhodes, 2014, s. 492-498. ISSN 1790-5117. ISBN 978-1-61804244-6 